\title{
OS CONTROLES, A CONFIANÇA E A ETICA NA GOVERNANÇA CORPORATIVA
}

\section{THE CONTROLS, THE TRUST AND THE ETHICS IN THE CORPORATE GOVERNANCE}

\author{
Carlos Frederico Trevia \\ Pontifícia Universidade Católica do Rio de Janeiro (IAG/PUC - Rio) - Rio de Janeiro - RJ \\ ctrevia@yahoo.com.br
}

\author{
Sandra Regina da Rocha-Pinto \\ Pontifícia Universidade Católica do Rio de Janeiro (IAG/PUC - Rio) - Rio de Janeiro - RJ \\ sregina.rochapinto@gmail.com
}

\section{Resumo}

Passaram-se mais de dezesseis anos do escândalo da Enron nos Estados Unidos e os problemas de Governança Corporativa continuam. Recentemente no Brasil as notícias da operação Lava-Jato, envolvendo a corrupção em grandes empresas, mancharam suas imagens. O desenvolvimento da Governança Corporativa se torna assunto focal das empresas perante a falta de confiança dos mercados financeiros nas organizações e em seus processos de tomada de decisão não-transparentes, sem a clara responsabilização dos decisores, em meio à descoberta de diversas fraudes em projetos de investimentos financiados por instituições financeiras ou por seus acionistas, resultando em perda do grau de investimento e queda do preço das ações de empresas de capital aberto. Os mecanismos tradicionais de Governança Corporativa e os controles formais não enxergam todo o processo de tomada de decisão e se mostraram insuficientes para reduzir riscos. A cada dia a sociedade convive com mais sistemas abstratos, de modo que confiança, a etica e 0 controle social passam a ser condições essenciais para a redução de custos de controle e a geração de resultados. O objetivo deste artigo é apresentar um Quadro de Referência para aplicação no campo dos estudos organizacionais, em pesquisas empíricas, visando ao estabelecimento de uma Governança Corporativa com uma visão mais abrangente para as empresas, contribuindo para que se alcance um novo nível de Governança que traga benefícios aos acionistas e as sociedades, com etica e responsabilidade social. Para tanto, apresenta-se uma revisão bibliográfica sobre os problemas de Governança Corporativa enfrentados nas empresas e os mecanismos que têm sido destacados na literatura e propostos para a abordagem do problema.

Palavras-chaves: Controle; Confiança; Ética; Governança Corporativa.

\section{Abstract}

It has been more than sixteen years from the Enron scandal in the United States and the corporate governance problems keep on going. Recently in Brazil, news about the Lava-jato operation involving corruption in big companies blurred their images. The Corporate Governance development becomes the companies focal theme before financial markets lack of trust in the organizations and their decision making process that is not transparents, without the clear accountability of the decision makers, while investment project frauds are discovered, being financed by financial institutions or by its shareholders, resulting in investment grade being lost and in stock price fall. The corporate governance traditional mechanisms and formal controls do not see the whole decision making process and are insufficient to reduce the risks. Day 
after day the society have to deal with more abstracts systems, in a way that trust, ethics and social control became essential conditions for the reduction of control costs and profit generation. The objective of this article is to present a framework to be applied in the organizational studies field, in the empirical research, in search of a corporate governance not shortsighted, in the companies, promoting a new level of governance that brings benefits to the shareholders, the society, with ethics and social responsibility. A bibliographical revision is presented about the corporate governance problems dealt with by the companies and the mechanisms that have been presented in the academy and suggested to deal with the problem.

Keywords: Control; Trust; Ethics; Corporate Governance.

\section{Introdução}

O desenvolvimento da Governança Corporativa é um assunto que é foco das empresas perante a crise de confiança atual gerada nos mercados com os escândalos de corrupção que dissiparam a confiança das pessoas nas organizações e em seus processos, em meio à descoberta de diversas fraudes em licitações e em seus investimentos. Tal crise ainda foi agravada pela perda do grau de investimento de empresas de capital aberto e queda nos preços das ações (VIOLANTE, 2015).

O interesse pelo estudo da confiança na Governança Corporativa tem aumentado diante da evidência das fragilidades dos sistemas de governança corporativa e de que o tema gera benefícios importantes para as organizações como a redução de custos de controle (DURDEN; PECH, 2006). Nota-se que os controles formais se mostraram insuficientes para reduzir o risco e gerar resultados. A confiança e a etica passam a serem condições essenciais para a sociedade, que a cada dia convive com mais sistemas abstratos.

Para esse artigo, uma revisão bibliográfica foi realizada por meio de uma pesquisa pelos termos Governança Corporativa (Corporate Governance), Confiança (Trust) e Responsabilização (Accountability) em inglês, no período de 2000 a 2016, na base Web of Science, áreas de negócios e de gestão. 0 período reflete a produção acadêmica e a evolução da gestão e das empresas após o escândalo da Enron nos Estados Unidos. $O$ foco foi em negócios e gestão, pois não se buscam evoluções técnicas, como, por exemplo, mecanismos contábeis, legais, etc. A pesquisa resultou em 13 artigos, sendo sete com foco em gestão, controle/ confiança e etica.

As discussões são apresentadas basicamente em ordem cronológica de modo a explicitar a evolução da discussão teórica no período. Com esta apresentação, foi possível notar uma guinada na academia, de uma visão positivista ferramental para uma visão mais interpretativa compreensiva. Conforme apresentado nos próximos tópicos, a evolução da teoria conduz a um arcabouço mais compreensivo para o problema, para além do estabelecimento de ferramentas de gestão e do aumento dos controles formais.

Como objetivo final, se buscou estabelecer um arcabouço conceitual de análise da Governança Corporativa de forma abrangente e inovadora, permitindo a busca por novos sistemas de governança mais compreensivos e que serão capazes de complementar a visão de controle que ainda é o foco das empresas.

Com este Quadro de Referência poderemos realizar um estudo de caso em uma organização para verificar como ela está lidando com os problemas de Governança Corporativa, quais medidas a organização está tomando e que resultados a organização está obtendo, frente ao que a literatura está prescrevendo, e o que poderia se apreender diretamente da prática.

O artigo está dividido em dez partes: Esta introdução; Os impactos do aumento de controles; A eficácia dos controles; Responsabilização em práticas de Governança Corporativa; Uma perspectiva etica para Governança Corporativa; Um sistema etico de relações pactuadas para construção de confiança; Auditoria interna como um parceiro estratégico na integração de processos; Reparando a confiança nas organizações; Uma visão abrangente para a Governança Corporativa; e a Conclusão.

\section{Os impactos do aumento de controles}


Estudos em Governança Corporativa não levam em conta os efeitos que o estabelecimento de regras causa na gestão da organização e no processo decisório (SOOBAROYEN; SHEIK-ELLAHI, 2008). As diversas medidas criadas para aumentar os controles levaram a consequências não previstas, como o estímulo a uma mentalidade legalista, preocupada com a forma e não com a substância do que é reportado, junto com 0 medo de desobedecer regras (DURDEN; PECH, 2006). Pesquisas demonstraram que o aumento dos controles impuseram custos significativos às organizações e os benefícios foram incertos, enquanto que a busca pela etica, com o comprometimento, pelos gerentes, com o comportamento socialmente responsável, levou a melhores resultados (DURDEN; PECH, 2006). Por exemplo, como uma das formas de mudança cultural realizada, os gerentes buscam maior credibilidade por meio do desenvolvimento de uma forma sociabilizada de responsabilização, com o aumento da comunicação, do diálogo e da confiança, levando a melhores resultados (SOOBAROYEN; SHEIK-ELLAHI, 2008). Por outro lado, em contextos onde os gerentes buscam objetivos contraditórios - como nos conflitos de agência - e há resistência, estes benefícios são reduzidos (SOOBAROYEN; SHEIK-ELLAHI, 2008).

O aumento dos controles, como defendem Durden e Pech (2006), não impede que más ações sejam realizadas, devido às fraquezas nos sistemas, as quais possibilitam a manipulação e o abuso no seu uso. Os autores explicam que os controles são necessários, de modo a diminuir o incentivo às más ações e facilitar a governança transparente e conforme, no entanto, as más ações não devem gerar um aumento constante nos custos para a realização do controle e para a busca da conformidade pelos gerentes. A Governança Corporativa deve ser vista como um processo, e não como uma ferramenta de controle definida pela alta administração, como no estudo de Soobaroyen e Sheik-Ellahi (2008).

Durden e Pech (2006) propõem então três medidas para mitigar essas consequências não previstas: o foco na gestão e na motivação ao invés do foco nos controles; o foco no desenho organizacional para não sobrecarregar as áreas com tarefas de controle excessivas; e o foco na flexibilidade, ao invés da burocracia, no processo decisório. Em linha com estes autores, Soobaroyen e Sheik-Ellahi (2008) propõem uma abordagem mais ampla, com o uso de diversas teorias que possam contribuir para melhorar a governança. Assim, estas e outras proposições são discutidas nos próximos tópicos deste artigo de modo evolutivo, com a proposição ao final do Quadro de Referência.

\section{A eficácia dos controles}

A discussão acadêmica sobre os problemas da Governança Corporativa começa com as questões ferramentais e de controle, que mais à frente, na evolução da discussão teórica, foram, se não superadas, importantemente complementadas com uma discussão etica.

Cohan (2002), na esteira dos escândalos ocorridos, discute a dinâmica interna das empresas, a qual contribuiu para as condições de falta de conhecimento sobre as más ações pelos Conselhos de Administração e Fiscal e a sociedade. Segundo ele, a habilidade dos Conselhos em monitorar efetivamente a conduta nos níveis operacionais se deve a varias situações, quais sejam: 0 isolamento da alta administração; os agentes perseguindo objetivos locais ou próprios em detrimento dos objetivos gerais da organização; o fluxo de informação por meio de um canal estreito que impede a informação adversa de chegar à alta administração; uma cultura de intimidação e desencorajamento sobre expressões de dúvida ou ceticismo, resultando em relutância em desafiar os altos executivos e levando o processo ao limite da etica e da lei.

Com relação à falta de informação pelos decisores, segundo Cohan (2002), responsabilizar os conselheiros por não enxergarem falhas nos processos é extremamente difícil. Segundo o autor, o bloqueio da informação envolve a lei da diminuição do controle, na qual há uma dissimulação deliberada na informação por gerentes, uma motivação para relatar ao chefe o que ele deseja ouvir, e a existência de uma irracionalidade no processo decisório, com motivações e emoções inconscientes, conforme explica a Teoria da Racionalidade Limitada. Esta discussão esta presente na Teoria da Estruturação de Giddens e no Behaviorismo de Habermas e podem contribuir muito para o estudo dos problemas relacionados à Governança Corporativa, 
bem como a discussão presente nas teorias que versam sobre temas como a dissonância cognitiva, a perseverança, o enviesamento, a racionalização, a coesão de grupo, o efeito do falso consenso e a tendência de fazer publicidade em termos exagerados com a desconsideração de riscos na divulgação de informação para mídia.

Ainda na linha positivista, focando em trabalhar o ferramental interno, e do ponto de vista da alta administração, Cohan (2002) resume as soluções vislumbradas até então com relação à forma como as companhias podem se estruturar, de modo que o Conselho possa monitorar o ambiente interno e descobrir e corrigir problemas antes deles tomarem vulto. Para ele, as empresas precisam implementar programas para: os empregados denunciarem mal feitos; desenvolver sistemas de comunicação que garantam a fidedignidade da informação para tomada de decisão; fazer com que os empregados conheçam a natureza de seus projetos e saibam o que os demais empregados fazem nos mesmos projetos; informar sobre como evitar conflitos de interesse e obedecer à lei.

Estas medidas precisam ser minimamente complementadas com proposições a partir de outros pontos de vista teóricos. Cumprir a Lei ou a regras não seria suficiente, segundo Roberts (2001). Soluções para melhorar o fluxo de informação podem incluir programas que encorajem, mais do que estimulem, os empregados a expor malfeitos sem medo de retaliação, com a concepção de um sistema de comunicação que viabilize que a informação importante chegue aos tomadores de decisão sem distorção, além da reestruturação do Comitê de Auditoria para que tenha uma função mais estratégica e integradora, do treinamento de novos conselheiros e do aumento do numero de conselheiros independentes, no sentido de as empresas terem representantes de cada parte interessada em seus Conselhos. É necessário evitar a politização da empresa (NADER, 1976, apud COHAN, 2002), requerendo a presença de representantes dos grupos de interesse nos Conselhos, e contratar empregados com inteligência emocional.

A inteligência emocional é importante para que se decida levando em conta a emoção. A emoção tem o potencial de contribuir para o processo decisório, ao invés de sabotá-lo (COHAN, 2002). Para Cohan (2002), as emoções emolduram a lógica e permitem alcançar uma busca balanceada pela verdade, que depende não somente da análise de evidências concretas, mas a verificação das sensitividades emocionais que afloram. Para o autor, quando não se sabe a verdade, ao confiar na validade das intuições, os decisores podem utilizar, e não suprimir, poderosos sentimentos que ajudam na tomada de decisão. Por outro lado, 0 autor alerta que o uso abusivo e errado da emoção, com explosões de raiva, soco na mesa etc, na tentativa de impedir o questionamento crítico, cria uma cultura que denigre o discurso legitimo e limita a busca pela verdade. Sem uma cultura adequada, mesmo quando é possível falar e argumentar, a gerência pode tratar essa abertura de forma dissimulada e reagir veladamente, tratando com descaso as denúncias (COHAN, 2002) e não fazendo com que a informação flua até os decisores. A mera existência da estrutura hierárquica impede que os agentes obtenham o conhecimento completo necessário para tomar decisões moralmente informadas e os impede de exercerem seus papéis no esquema corporativo maior, e até podem estar contribuindo para as más ações (COHAN, 2002). Assim, é importante que os Conselheiros não tenham medo de desafiar a alta administração fazendo perguntas ditas inconvenientes (COHAN, 2002).

Cohan (2002) vai além, e afirma também que a informação precisa ir além dos decisores. Para o autor, as empresas devem atender as expectativas das partes interessadas por maior responsabilização, e que 0 bem social algumas vezes supera a noção de maximização do lucro, pois o verdadeiro motivo da existência de uma empresa é contribuir para uma sociedade melhor e criar riqueza social, não apenas criar riqueza para o acionista. Assim, é preciso um balanço de um modelo centrado nas partes interessadas e de um modelo centrado nos acionistas, gerando um modelo de constituição da organização, que foca no interesse da corporação de forma estendida, representando os vários interessados.

\section{Responsabilização em práticas de Governança Corporativa.}

Em linha com a evolução da discussão proposta por Cohan (2002), Roberts (2001) reformula o problema da Governança Corporativa por meio de uma mudança do foco analítico, dos problemas de assegurar os interesses de donos distantes para um entendimento do processo de responsabilização. 0 autor insere 
então na discussão a questão da socialização. Ele faz uma distinção entre processos e práticas de responsabilização em termos de seus efeitos de individualização ou de socialização. Segundo ele, efeitos de individualização são voltados para a responsabilização hierárquica, envolvendo a produção e reprodução do self como singular e solitário, com uma relação instrumental com outros. Já os efeitos de socialização envolvem responsabilização cara-a-cara entre pessoas de poder relativamente igual, constituindo um senso de interdependência instrumental e moral. Criticando o aumento dos controles, 0 autor defende uma nova abordagem em que, em vez de ficar criando mecanismos para controlar as pessoas, devem-se expor as pessoas às interações, gerando um efeito de controle que gerará melhores resultados. Como ele diz, um dos benefícios da responsabilização cara-a-cara entre relativamente iguais - as formas sociabilizadas de responsabilização - é que nos permite testar e desafiar nossas premissas e a dos outros por meio do diálogo. Esta responsabilização cara-a-cara é fonte de aprendizado e pode produzir relações complexas de confiança, respeito e obrigação recíproca, que supere em muito a orientação puramente instrumental para a ação que a Teoria da Agência assume. Em suma, é como dizer que se as pessoas podem se colocar livremente, sem pressões hierárquicas, argumentando e deixando claro suas posições, em interações verdadeiras e honestas. Essa condição, por si só resolveria as questões referentes a interesses pessoais e a natureza humana ruim, a qual a Teoria da Agência assume que é fonte dos problemas de governança e do processo decisório, quando tais mecanismos são mau usados visando implementar decisões a partir de interesses pessoais e em detrimento dos interesses dos acionistas e das partes interessadas (stakeholders), buscando o bem comum. Como Roberts (2001) considera, é a necessidade de processos efetivos corporativos de responsabilização, mais do que o controle de agentes com interesses próprios, que define o problema da Governança Corporativa. Se, para as premissas da Teoria da Agência, as falhas de governança podem ser somente remediadas pela intensificação dos controles internos e externos, a visão de todo o processo de governança sugere que potenciais efeitos positivos podem ser alcançados por meio do aumento da responsabilização externa, enquanto reforço das formas sociabilizadas de responsabilização dentro da empresa. Estas mudanças para um foco de cobrança interno e interdependente pode permitir a criação de processos de responsabilização que encorajem o diálogo aberto, e que permita aos decisores 0 balanço entre a busca pelo lucro e o reconhecimento de responsabilidades maiores com os empregados e as comunidades. $O$ maior efeito prejudicial da individualização no processo de responsabilização é que promove uma preocupação com a pessoa ao invés de uma noção de dependência recíproca. A efetividade do processo de sociabilização (troca social) da responsabilização sempre dependerá da vontade dos indivíduos de arriscar o exercício da voz, mas, se visto como um processo de aprendizado, esta responsabilização tem 0 potencial de reforçar a noção sobre dependência e tornar este processo gerenciável.

\section{Uma perspectiva etica para Governança Corporativa.}

Em seguida à discussão feita por Roberts (2001) sobre a responsabilização, Potts e Matuszewski (2004), adicionam uma nova definição, a responsabilização etica. Experientes em medidas corretivas e no clamor público por responsabilização etica nas organizações, os autores concluem que é essencial que a etica seja parte integral da cultura da organização. Isto significa que o simples enxerto superficial de um código de etica nos sistemas administrativos não irá impulsionar a mudança organizacional ou encorajar a confiança do público. Segundo os autores, os líderes precisam modelar um processo etico, como um processo por completo de mudança de cima para baixo promovido pela alta administração. É possível concordar com a visão de Potts e Matuszewski (2004) sobre o papel dos líderes, porém, considerando a visão de Roberts (2001), este processo deveria ocorrer muito mais de forma interacional, entre atores, num processo de sociabilização. Assim, ainda que a cultura etica ocorra com o auxílio de alguns mecanismos corporativos facilitadores, conclui-se que, em se tratando de uma necessidade de uma mudança na cultura, essa mudança para uma cultura etica não se faria por determinação, mas, pela prática. Segundo Potts e Matuszewski (2004), quando a etica é parte da cultura organizacional, irá prevenir problemas e resolvê-los quando eles aparecerem. Para eles, sempre haverá maus agentes, mas uma maior transparência e padrões eticos altos irão isolar e expor os corruptos. Eles também afirmam que companhias reconhecidas como 
eticas irão recrutar e reter a melhor força de trabalho e fomentarão relações positivas e de longo prazo com vendedores, clientes e acionistas.

Assim, como complemento aos autores citados, Arjoon (2005) leva a discussão para um nível estratégico. $O$ autor ressalta a necessidade de se alcançar uma perspectiva estratégica para a etica, que se sobreporia tanto aos controles (individualização) como ao processo de tomada de decisão por meio de argumentação e aprendizado coletivo (sociabilização). Arjoon (2005) discute as questões de Governança Corporativa a partir de um ponto de vista da conformidade, fazendo uma distinção entre mecanismos de conformidade legal e de conformidade etica, mostrando que a conformidade legal tem claramente se mostrada inadequada ao Ihe faltar o poder de fogo moral para restaurar a segurança e a habilidade de construir confiança. Para ele, alguns conceitos relacionados à liberdade de atuação, chamados por ele de "liberdade da indiferença" e "liberdade para a excelência", proveem uma base teórica para explicar o porquê de a conformidade legal ser insuficiente em lidar com práticas fraudulentas e não endereçar a real e fundamental questão que inspira o comportamento etico. Significa dizer que, por exemplo, enquanto os executivos não se libertarem da busca por lucro a qualquer custo, não é possível instigar ou praticar um comportamento $100 \%$ etico. Segundo 0 autor, a tendência de enfatizar demais mecanismos de conformidade legal pode resultar numa tentativa de substituir responsabilização por responsabilidade. Quer dizer, a Governança Corporativa preocupa-se com quem pode fazer o quê e não com quem fez o quê. A esse respeito, pode-se trazer um exemplo no qual a Governança Corporativa define como regra que um Diretor pode tomar decisões importantes, em conformidade com as leis, mas a Governança Corporativa usualmente não se preocupa com a qualidade das decisões dele, suas motivações e seus efeitos. Com esse exemplo, pode-se notar que o ambiente atual de fracassos de responsabilidade corporativa não é somente um ambiente de fracasso de conformidade legal, mas fundamentalmente falhas em fazer a coisa certa (eticamente falando).

Arjoon (2005) conclui afirmando que, com uma Governança Corporativa efetiva, baseada em valores centrais de integridade e confiança, as companhias terão vantagem competitiva em atrair e reter talento e gerar reações positivas nos mercados. Para ele, Governança Corporativa efetiva pode ser alcançada pela adoção de um conjunto de princípios e melhores práticas, que envolvem razoabilidade, honestidade, integridade, e a maneira como fazem negócios, mantendo a busca pelo lucro dentro das fronteiras eticas. As companhias devem adotar também políticas que incluem proteção do meio ambiente, canais e cultura de denúncia, programas de treinamento etico, etc. Tais mecanismos de conformidade etica contribuem para a estabilidade e para o crescimento à medida que eles geram segurança. Por fim, há a necessidade de integrar a lei e a etica de modo que as companhias poderão navegar em áreas cinza se mantendo no lado certo da lei, mesmo quando a regra da lei for ambígua ou onde a empresa não saiba da aplicação da lei (SEIDMAN, 2004, apud ARJOON, 2005). Para Arjoon (2005), embora códigos de etica e execução disciplinada sejam instrumentos importantes, não contêm o poder emocional final do comprometimento com objetivos de qualidade - com a lei e altos padrões eticos -, que são inspirados mais pelo orgulho do que pelo lucro. Uma vez que o escopo das decisões estratégicas se alarga, seu componente etico não está mais em desacordo com uma decisão correta (KENNETH ANDREWS, 1989, apud ARJOON, 2005).

\section{Um sistema etico de relações pactuadas para construção de confiança}

Contribuindo para a visão da etica como estratégica em linha com Arjoon (2005), Caldwell e Karri (2005) detalham a questão etica pela perspectiva da geração de confiança. Segundo eles, expectativas crescentes por melhor responsabilização acompanham o declínio em confiança. As formas tradicionais de resolução dos problemas de Governança Corporativa, tipificadas pela Teoria da Agência e Teoria das Partes Interessadas (Stakeholders), têm sido caras para se implementar e têm se focado no lucro no curto prazo e nas falhas dos sistemas organizacionais em alcançar os resultados. Eles concordam que estas teorias de governança organizacionais são inadequadas para construir confiança. Eles então apresentam sua Teoria do Procurador (Stewardship), caracterizada por relações pactuadas, tanto transacionais como psicológicas, e argumentam que o desenho dos mecanismos de governança usando a forma pactuada é mais efetivo em construir confiança. Uma relação pactuada é uma forma especializada de contrato relacional entre empregados e sua organização. Eles argumentam que a despeito de incentivos e de mecanismos de 
controle cuidadosamente desenhados por meio de mecanismos contratuais, na ausência de relações pactuadas é extremamente difícil construir confiança. Eles propõem que as empresas terão mais chance de construir confiança no nível organizacional e interpessoal quando elas criam sistemas de reforço e integração que honrem os compromissos estabelecidos pelas relações pactuadas.

Caldwell e Karri (2005) fazem uma comparação da Teoria da Agência e da Teoria das Partes Interessadas com a sua Teoria do Procurador. A distinção da Teoria do Procurador para a Teoria da Agência e para a Teoria das Partes Interessadas é que segundo eles, a Teoria do Procurador é um modelo eticamente superior porque honra as obrigações sociais e os deveres com todas as Partes Interessadas. Para eles, a força da abordagem pactuada da Teoria do Procurador é que incorpora a habilidade de olhar internamente (individual e organizacionalmente) e em direção ao ambiente externo, ao acessar as necessidades organizacionais no contexto geral, o que constituiria o duplo ciclo de aprendizado de Argyris e Schon (1978). Senge (1990), ao ressaltar a importância do aprendizado organizacional, estaria corroborando para essa superioridade presente na Teoria do Procurador. A abordagem pactuada para a Governança Corporativa, sugerida pela Teoria do Procurador, desafia profundamente os líderes corporativos, segundo Caldwell e Karri (2005), porque presume o controle compartilhado, e foca em valores e não em técnicas.

Assim, Caldwell e Karri (2005) defendem que se deve olhar de perto os princípios com os quais as corporações são governadas e ajustar seus modelos. Os autores também propõe que a academia estude os modelos mentais de etica dos executivos corporativos, Conselhos de Administração, gerentes e empregados no contexto das teorias de governança de modo a entender como a Teoria do Procurador pode se tornar um novo sistema de Governança Corporativa.

\section{Auditoria Interna como um parceiro estratégico na integração de processos.}

Considerando a visão estratégia expandida, a qual inclui a etica, medidas de sociabilização, de geração de confiança e as relações pactuadas, Savcuk (2007) em adição contribui para a uma nova visão no que tange aos aspectos dos controles, já tão rechaçado por Roberts (2001). Segundo a autora, a resposta da gestão envolve, além da maior responsabilização, o gerenciamento de risco e a reengenharia de estruturas e de processos, para que se tenha informação relevante no tempo necessário e de forma confiável para 0 processo decisório, assegurando a confiança dos investidores. Segundo ela, uma forte Governança Corporativa na gestão de riscos pode ser obtida com essas medidas e com cada empresa desenvolvendo e implementando uma forma de acessar e gerenciar as incertezas, pois os acionistas cobram da administração informações sobre suas atividades e querem um acesso independente à gestão de risco e ao sistema de governança. Para alcançar este objetivo, a Auditoria Interna se desenvolveu de uma função de controle responsável por inspecionar os dados contábeis e financeiros, para ser um parceiro estratégico para os acionistas e para a administração no desenvolvimento dos processos de governança, pois os acionistas confiam à Auditoria Interna a tarefa de avaliar se os controles são suficientes para gerenciar riscos e incertezas (SAVCUK, 2007). Segundo Savcuk (2007), a Auditoria Interna tem um papel importante na integração de diversos aspectos de controle e de governança e se configura como o mais importante mecanismo único para assegurar uma governança adequada e efetiva para a organização. Este papel ampliado da Auditoria Interna se constitui a partir de uma visão mais processual da Governança Corporativa, contribuindo para o foco nos processos de responsabilização via sociabilização (ROBERTS, 2001) e em detrimentos dos aspectos de controle das pessoas, se configurando como um caminho complementar para resolução dos problemas de governança.

\section{Reparando a confiança nas organizações}

É possível notar que a confiança é considerada em diversas abordagens inovadoras que vão além dos controles para tratar a Governança Corporativa. Bachmann et al (2015) confirmam que a confiança tem um papel fundamental na facilitação da sociabilização. Os escândalos ocorridos nas empresas têm prejudicado a confiança nas empresas. Fica a pergunta de como reparar esta confiança. Segundo os autores, a literatura tem focado no nível micro, limitadamente examinando como estes processos operam no nível macro e entre 
níveis. Ao invés de focar na sociabilização como solução, como Roberts (2001), Bachmann et al (2015) concluem que não se pode confiar em nenhum mecanismo isolado para reconstruir a confiança. Seu modelo inclui: controles - os quais Roberts (2001) descredencia como capaz de resolver os problemas de governança; elementos de sociabilização (ROBERTS, 2001) tais como a cognição (o aprendizado coletivo) e o relacionamento (com exposição de cada agente); a cultura etica (que se constituem como controles informais); a transparência (divulgação de informação e responsáveis); e a transferência (que é a passagem de credibilidade de uma parte para outra). Essas medidas quando desenvolvidas conjuntamente contribuem para a geração de confiança.

\section{Uma visão abrangente para a Governança Corporativa}

A partir da revisão bibliográfica, entende-se que o posicionamento teórico mais adequado para abordagem do problema da Governança Corporativa é uma visão mais compreensiva, substantiva e interpretativa, na medida em que tira o peso das ferramentas de gestão e enfatiza o olhar crítico sobre a natureza das pessoas, suas motivações, e como se dão seus relacionamentos, e, por fim, como se dá o processo de tomada de decisão. Este posicionamento teórico segue principalmente: a linha de Roberts (2001), com a sua sociabilização; sendo também discutida em certos aspectos por Cohan (2002), quando aborda a irracionalidade na tomada de decisão e, primordialmente, quando questiona a maximização do lucro; o que Caldwell e Karri (2005) também ressaltam, pregando um olhar para o ambiente externo e ampliando 0 conceito de organização constituinte, considerando o modelo de duplo ciclo de aprendizado, e ao discutir as relações pactuadas e focar em valores, mais do que em técnicas, propondo o estudo dos modelos mentais eticos dos agentes e a criação de um novo sistema de Governança Corporativa; como Arjoon (2005), que afirma da inadequação de se buscar uma conformidade legal e propõe uma conformidade etica e uma Governança Corporativa baseada em valores de integridade e confiança; e também Bachmann et al (2015), que afirma que a confiança tem um papel fundamental na troca social e deve ser restaurada com base em uma série de mecanismos.

Assim, considerando essa nova forma de ver e tratar a Governança Corporativa, a pesquisa empírica poderá fazer uso desse modelo conceitual com o Quadro de Referência de Bachmann et al (2015), que indica seis mecanismos para abordagem do problema de má Governança, agregando a ele as premissas dos compromissos pactuados da Teoria do Procurador, de Caldwell e Karri (2005), que detalha a dimensão etica de Bachmann et al (2015), bem como os requisitos de conformidade etica de Arjoon (2005). O Quadro de Referência mais compreensivo é apresentado no Quadro 1.

Como é possível notar, algumas questões vêm sendo discutidas pela literatura, do nível micro (operacional) em direção ao nível macro (estratégico), e podem contribuir para a resolução de problemas de governança, tais como: Aumentar os controles resolve as fraudes e a corrupção?; Como ter confiança nos empregados?; O que precisa ser feito para que se possa confiar nas empresas?; Que outros mecanismos contribuem para uma boa prática em Governança Corporativa?; Como se pode alcançar uma Governança Corporativa adequada?

De modo a contribuir para a literatura e para as empresas, sugere-se a realização de pesquisas de campo, para verificar a aplicação dos mecanismos de reestabelecimento da confiança e de conformidade etica, conforme Quadro 1, os quais podem demonstrar uma boa prática de governança. As pesquisas poderão ter abordagens exploratórias (de forma complementar à teoria levantada), descritivas (descrevendo os problemas enfrentados na prática e seus ambientes e inter-relações), e explanatórias (para entender 0 porquê e o como se dá a má e a boa Governança Corporativa).

A limitação teórica pode se dar principalmente pela complexidade da integração de teorias sociológicas e psicológicas - considerando suas profundidades teóricas - com as teorias de gestão, o que levará em alguns aspectos ao tratamento superficial das questões encontradas em campo. Não obstante, sem dúvida, têmse a oportunidade de estabelecer um arcabouço conceitual de análise de forma mais abrangente, crítica e inovadora para os problemas da Governança Corporativa, permitindo a busca por novos sistemas de governança mais compreensivos e que serão capazes de complementar a visão de controle que ainda é o 
foco das empresas.

\begin{tabular}{|c|c|c|c|c|c|c|c|}
\hline $\begin{array}{l}\text { Mecanis } \\
\text { mos }\end{array}$ & $\begin{array}{l}\text { Processos } \\
\text { de } \\
\text { Entendime } \\
\text { nto }\end{array}$ & $\begin{array}{l}\text { Relaciona } \\
\text { mento }\end{array}$ & Controles & $\begin{array}{l}\text { Cultura } \\
\text { Etica }\end{array}$ & $\begin{array}{l}\text { Transparên } \\
\text { cia }\end{array}$ & Transferência & $\begin{array}{l}\text { Conformi } \\
\text { dade } \\
\text { Etica }\end{array}$ \\
\hline $\begin{array}{l}\text { Premiss } \\
\text { a }\end{array}$ & $\begin{array}{l}\text { Entendimen } \\
\text { to } \\
\text { compartilha } \\
\text { do sobre } \\
\text { violação de } \\
\text { confiança. }\end{array}$ & $\begin{array}{l}\text { Rituais e } \\
\text { atos } \\
\text { simbólicos } \\
\text { para tratar } \\
\text { violações à } \\
\text { confiança. }\end{array}$ & $\begin{array}{l}\text { Controles } \\
\text { formais e } \\
\text { regras que } \\
\text { constrange } \\
\mathrm{m} \\
\text { comporta } \\
\text { mento não } \\
\text { confiável. }\end{array}$ & $\begin{array}{l}\text { Controles } \\
\text { culturais }\end{array}$ & $\begin{array}{l}\text { Compartilha } \\
\text { mento de } \\
\text { informação } \\
\text { com partes } \\
\text { interessadas }\end{array}$ & $\begin{array}{ll}\text { Migração de } & \text { confiança de } \\
\text { parte confiável }\end{array}$ & $\begin{array}{l}\text { Conjunto } \\
\text { de } \\
\text { princípios } \\
\text { eticos e } \\
\text { compromis } \\
\text { so com } \\
\text { valores da } \\
\text { sociedade }\end{array}$ \\
\hline Foco & $\begin{array}{l}\text { Cognição e } \\
\text { influência } \\
\text { Social }\end{array}$ & $\begin{array}{l}\text { Emoções e } \\
\text { Rituais } \\
\text { Sociais }\end{array}$ & $\begin{array}{l}\text { Organizaç } \\
\text { ão formal e } \\
\text { ambiente } \\
\text { institucion } \\
\text { al }\end{array}$ & $\begin{array}{l}\text { Organizaç } \\
\text { ão } \\
\text { informal e } \\
\text { contexto } \\
\text { cultural }\end{array}$ & $\begin{array}{l}\text { Relatórios e } \\
\text { indicadores }\end{array}$ & $\begin{array}{l}\text { Envolvimento } \\
\text { de terceiros }\end{array}$ & $\begin{array}{l}\text { Integração } \\
\text { de valores } \\
\text { e criação } \\
\text { de riqueza } \\
\text { social }\end{array}$ \\
\hline Base & $\begin{array}{l}\text { Aprendizad } \\
\text { o Coletivo }\end{array}$ & $\begin{array}{l}\text { Remorso e } \\
\text { Redenção }\end{array}$ & $\begin{array}{l}\text { Controle } \\
\text { Formal }\end{array}$ & $\begin{array}{l}\text { Controle } \\
\text { Informal }\end{array}$ & $\begin{array}{l}\text { Compartilha } \\
\text { mento/ } \\
\text { responsabili } \\
\text { zação }\end{array}$ & Reputação & $\begin{array}{l}\text { Comporta } \\
\text { mento } \\
\text { Responsá } \\
\text { vel }\end{array}$ \\
\hline $\begin{array}{l}\text { Área } \\
\text { Teórica }\end{array}$ & $\begin{array}{l}\text { Teoria } \\
\text { Organizacio } \\
\text { nal }\end{array}$ & $\begin{array}{l}\text { Psicologia } \\
\text { e } \\
\text { Sociologia }\end{array}$ & $\begin{array}{l}\text { Sociologia, } \\
\text { Gestão e } \\
\text { Ciência } \\
\text { Organizaci } \\
\text { onal }\end{array}$ & $\begin{array}{l}\text { Filosofia, } \\
\text { Ciência } \\
\text { organizaci } \\
\text { onal e } \\
\text { Gestão }\end{array}$ & $\begin{array}{l}\text { Gestão } \\
\text { Pública e } \\
\text { Governança } \\
\text { Corporativa }\end{array}$ & $\begin{array}{l}\text { Redes Sociais } \\
\text { e Sociologia }\end{array}$ & Sociologia \\
\hline $\begin{array}{l}\text { Autores } \\
\text { de } \\
\text { referênci } \\
\text { a }\end{array}$ & $\begin{array}{l}\text { Gillespie \& } \\
\text { Dietz (2009) } \\
\text { Kim et al } \\
(2006, \\
2009) \\
\text { Mueller et al } \\
\text { (2015) } \\
\text { Pfarrer et al } \\
\text { (2008) } \\
\text { Tomlinson \& } \\
\text { Mayer } \\
\text { (2009) }\end{array}$ & $\begin{array}{l}\text { Bottom et al } \\
(2002) \\
\text { Kim et al } \\
(2009) \\
\text { Gillespie \& } \\
\text { Dietz } \\
(2009) \\
\text { Pfarrer et al } \\
\text { (2008) } \\
\text { Stevens et } \\
\text { al (2015) } \\
\text { Ren \& Gray } \\
\text { (2009) } \\
\text { Shapiro } \\
\text { (1991) } \\
\text { Tomlinson } \\
\text { et al (2004) }\end{array}$ & $\begin{array}{l}\text { Bachmann } \\
\& \quad \text { Inkpen } \\
(2011) \\
\text { Eberl et al } \\
\text { (2015) } \\
\text { Gillespie \& } \\
\text { Dietz } \\
\text { (2009) } \\
\text { Nakayachi } \\
\text { \& Watabe } \\
\text { (2005) } \\
\text { Sitkin (\& } \\
\text { Roth } \\
\text { (1993) } \\
\text { Weibel } \\
\text { (2007) }\end{array}$ & $\begin{array}{l}\text { Bridoux \& } \\
\text { Stoelhorst } \\
\text { (2014) } \\
\text { Eberl et al } \\
\text { (2015) } \\
\text { Gillespie \& } \\
\text { Dietz } \\
\text { (2009) } \\
\text { Harris\&Br } \\
\text { omley } \\
\text { (2007) } \\
\text { Harrison } \\
\text { et al } \\
\text { (2010) }\end{array}$ & $\begin{array}{l}\text { Augustine } \\
\text { (2012) } \\
\text { Child \& } \\
\text { Rodrigues } \\
\text { (2004) } \\
\text { Grimmelikhu } \\
\text { ijsen et al } \\
(2013) \\
\text { Pirson et al } \\
(2014)\end{array}$ & $\begin{array}{l}\text { Coleman } \\
(1990) \\
\text { Ferrin et al } \\
(2006) \\
\text { Krackhardt } \\
(1992) \\
\text { Mueller et al } \\
(2015) \\
\text { McEvily et al } \\
\text { (2003) } \\
\text { Spicer\&Okhm } \\
\text { atovskiy (2015) }\end{array}$ & $\begin{array}{l}\text { Caldwell \& } \\
\text { Karri } \\
(2005) \\
\text { Arjoon } \\
(2005) \\
\text { Potts \& } \\
\text { Matuszew } \\
\text { ski (2004) }\end{array}$ \\
\hline
\end{tabular}




\begin{tabular}{|c|c|c|c|c|c|c|c|}
\hline $\begin{array}{l}\text { Escopo } \\
\text { das } \\
\text { Variáveis }\end{array}$ & $\begin{array}{l}\text { Investigaçõ } \\
\text { es, } \\
\text { questionam } \\
\text { entos } \\
\text { públicos, } \\
\text { explicações } \\
\text { e } \\
\text { responsabili } \\
\text { dades }\end{array}$ & $\begin{array}{l}\text { Explicaçõe } \\
\text { s, } \\
\text { apologias, } \\
\text { punições, } \\
\text { penas, } \\
\text { compensaç } \\
\text { ões, } \\
\text { distribuição } \\
\text { de poder, } \\
\text { estabeleci } \\
\text { mento de } \\
\text { expectativa } \\
\text { s }\end{array}$ & $\begin{array}{l}\text { Regulação } \\
\text { ' leis, } \\
\text { regras } \\
\text { organizaci } \\
\text { onais, } \\
\text { políticas, } \\
\text { controles, } \\
\text { contratos, } \\
\text { códigos de } \\
\text { conduta, } \\
\text { sanções e } \\
\text { incentivos }\end{array}$ & $\begin{array}{l}\text { Reformas } \\
\text { culturais, } \\
\text { indução e } \\
\text { socializaç } \\
\text { ão, } \\
\text { treinament } \\
0 \\
\text { profission } \\
\text { al, } \\
\text { modelage } \\
\text { m de } \\
\text { liderança } \\
\text { e papéis }\end{array}$ & $\begin{array}{l}\text { Relatórios } \\
\text { Corporativos } \\
\text { ' Auditoria } \\
\text { Externa, } \\
\text { Questionam } \\
\text { entos } \\
\text { públicos, } \\
\text { proteção à } \\
\text { denúncia }\end{array}$ & $\begin{array}{l}\text { Certificações, } \\
\text { associações, } \\
\text { afiliações, } \\
\text { Títulos, } \\
\text { prêmios, } \\
\text { endossos }\end{array}$ & $\begin{array}{l}\text { Riqueza } \\
\text { Social, } \\
\text { valores, } \\
\text { direitos, } \\
\text { liderança, } \\
\text { processo } \\
\text { decisório }\end{array}$ \\
\hline
\end{tabular}

Quadro 1 - Mecanismos para Governança Corporativa compreensiva

Fonte: Adaptado de Bachmann et al (2015), Caldwell e Karri (2005) e Arjoon (2005)

\section{Conclusão}

Foi possível identificar claramente uma guinada na teoria, que passou a abordar o problema da má Governança Corporativa de um ponto de vista teórico mais abrangente, e, portanto, capaz de ter uma visão mais acurada do problema. Fica claro que para resolver o problema da Governança Corporativa deve-se ir muito além da intensificação dos controles.

Para a literatura, este artigo contribui proporcionando uma visão mais clara da evolução da discussão teórica, a qual demonstra uma guinada na teoria e na pesquisa sobre Governança Corporativa - que parte incialmente de uma visão positivista e ferramental, a qual considera a natureza humana ruim e que deve ser controlada, olhando as organizações de cima para baixo, do ponto de vista dos acionistas e da alta administração - em direção à uma visão mais interpretativa, crítica, social, para além das fronteiras organizacionais e para além da visão simplista da natureza humana ruim, considerando suas diversas facetas e interdependências, olhando a organização a partir dos seus agentes, sua cognição, a socialização e seu ambiente.

Com esta visão abrangente, será possível se aproximar das respostas buscadas quanto à confiabilidade nas empresas, nos agentes e quais mecanismos são realmente capazes de propiciar uma boa prática de Governança Corporativa. As empresas poderão criar novos sistemas de Governança Corporativa e assim reestabelecer a confiança das partes interessadas e ampliar seu modelo de constituição para proporcionar riqueza social.

\section{Referências}

ARGYRIS, C.; SCHON, D. A. Organizational Learning: A Theory of Action Perspective. Addison Wesley, 1978.

ARJOON, S. Corporate Governance: An Ethical Perspective. Journal of Business Ethics. 61: 343-352, 2005.

BACHMANN, R et al. Repairing Trust in Organizations and Institutions: Toward a Conceptual Framework. Organization Studies. Vol, 36: 9, 1123-1142, 2015.

CALDWELL, C.; KARRI, R. Organizational Governance and Ethical Systems: A Covenantal Approach to Building Trust. Journal of Business Ethics, 58: 249-259, 2005.

COHAN, J.A. "I Didn't Know" and "I Was Only Doing My Job": Has Corporate Governance Careened Out of Control? A Case Study of Enron's Information Myopia. Journal of Business Ethics. 40: 275-299, 2002.

DURDEN, C.; PECH, R. The increasing cost of corporate governance: decision speed-bumps for managers. 
Corporate Governance: The international journal of business in society. Vol. 6 Issue: 1, pp.84-95, 2006. POTTS, S.D.; MATUSZEWSKI, I.L. Ethics and Corporate Governance. Ethics and Corporate Governance. Vol. 12, number 2, 2004.

ROBERTS, J. Trust and Control in Anglo-American systems of corporate governance: The individualizing and socializing effects of processes of accountability. Human Relations. Volume 54 (12); 1547 -1572, 2001. SENGE, P. M. The fifth discipline: The art \& practice of the learning organization. Doubleday Business, 1990.

SAVCUK, O. Internal audit efficiency evaluation principles. Journal of Business Economics and Management. Vol. VIII: № 4, 275-284, 2007.

SOOBAROYEN, T.; SHEIK-ELLAHI, A. A case study on the influence of corporate governance beyond the boardroom: perceptions from business unit managers. Corporate Governance: The international journal of business in society. Vol. 8 Issue: 2, pp.179-190, 2008.

VIOLANTE, C. Ações da Petrobrás têm forte queda após perda de grau de investimento. 0 Estado de São Paulo, São Paulo, 25 fev. 2015. Disponível em: <https://economia.estadao.com.br/noticias/mercados, acoesda-petrobras-tem-forte-queda-apos-perda-de-grau-de-investimento,1639384>. Acesso em: 21 jun. 2018. 